\title{
Killip Class IV
}

National Cancer Institute

\section{Source}

National Cancer Institute. Killip Class IV. NCI Thesaurus. Code C77272.

A classification of myocardial infarction characterized by cardiogenic shock; an event with systolic BP less than $90 \mathrm{mmHg}$ for greater than 30 minutes, not responsive to fluid resuscitation alone, and felt to be secondary to cardiac dysfunction. Associated signs of hypoperfusion (cool and clammy skin, oliguria, or altered sensorium) or a cardiac index of less than $2.2 \mathrm{~L} / \mathrm{min} / \mathrm{m} 2$ are present. This includes when the systolic BP increases to greater than $90 \mathrm{mmHg}$ in response to inotropic agents in less than 1 hour.) 